\title{
FAKTOR-FAKTOR YANG BERHUBUNGAN DENGAN TINDAKAN PENJAMAH DALAM PENANGANAN MAKANAN PADA RUMAH MAKAN DI KABUPATEN BANJAR
}

\author{
Perdana Oktavianus Kurniawan, Darmiah, Rahmawati \\ Poltekkes Kemenkes Banjarmasin Jurusan Kesehatan Lingkungan \\ Jl. H. Mistar Cokrokusumo No.1A Banjarbaru Kalimantan Selatan 70714 \\ E-mail: dana07101994@gmail.com
}

\begin{abstract}
The Factors Associated With Handler's Action In Handling Food On Restaurants In Banjar District. In 2015 there are poisoning cases because of contaminated food by chemical, physical, and biological factors. The case occurred in Gambut Subdistrict, Kertak Hanyar, Simpang Empat and Martapura, cause South Kalimantan in the sixth province with the highest poisoning case in Indonesia. The poisoning cases of $66.7 \%$ is caused by microbial contamination on fast food from the handlers. This is because their action who are less concerned on food safety, especially they work at house. This study aimed to determine the factors associated with the handler's action in handling food on restaurants in Banjar District. The study type was Observational Research with Cross sectional design. The method used interview and observation. The sample was determined by purposive sampling technique, which is obtained by research opinion, with the result obtain a sample amounted to 78 food handlers that work for 24 restaurants in Martapura, Banjar District. The results showed that there was significant relationship between: 1) the education and handler's action $(p<\alpha) ; 2)$ the training and handler's action $(p<\alpha) ; 3)$ the knowledge and handler's action $(p<\alpha)$; 4$)$ the attitude and handler's action $(p<\alpha)$ and there was no significant relationship between: 1) the duration of service and handler's action ( $p>\alpha)$; 2) the facility and handler's action $(p>\alpha)$. The suggestions are given to: 1) handlers to raise awareness on food safety and accustom themselves to implement proper personal hygiene practices correctly and regularly; 2) health workers to conduct training and extension devoted to food handlers and motivate managers and handlers to raise awareness on maintaining food safety; 3) For consumers to carefully choose a restaurant that not only provides cheap and tasty food, but also pay attention to the clean liness of the restaurant.
\end{abstract}

Keywords: Food handler's action; restaurant

Abstrak: Faktor-Faktor Yang Berhubungan Dengan Tindakan Penjamah Dalam Penanganan Makanan Pada Rumah Makan Di Kabupaten Banjar. Pada tahun 2015 terjadi kasus keracunan karena makanan yang tercemar oleh faktor kimia, fisik, dan biologi. Kasus tersebut terjadi di Kecamatan Gambut, Kertak Hanyar, Simpang Empat dan Martapura Kota sehingga menempatkan Kalimantan Selatan diurutan ke-6 provinsi dengan kasus keracunan tertinggi se-Indonesia. Sebesar $66,7 \%$ kasus disebabkan oleh kontaminasi mikroba pada makanan siap saji yang bersumber dari penjamah. Hal ini dikarenakan tindakan penjamah yang kurang peduli mengenai keamanan pangan khususnya yang bekerja di rumah makan. Tujuan penelitian ini untuk mengetahui faktor-faktor yang berhubungan dengan tindakan penjamah dalam menangani makanan pada rumah makan di Kabupaten Banjar. Jenis penelitian ini adalah observasional research dengan desain cross sectional. Metode yang digunakan yaitu wawancara dan observasi. Sampel ditentukan dengan teknik purposive sampling yakni berdasarkan pertimbangan tertentu, sehingga didapatkan sampel sebanyak 78 orang penjamah yang bekerja pada 24 buah rumah makan di Martapura Kota wilayah Kabupaten Banjar. Hasil penelitian menunjukan bahwa terdapat hubungan yang bermakna antara: 1) pendidikan dengan tindakan penjamah $(p<\alpha) ; 2)$ pelatihan dengan tindakan penjamah $(p<\alpha)$; 3) pengetahuan dengan tindakan penjamah $(p<\alpha)$; 4) sikap dengan tindakan penjamah $(p<\alpha)$ dan tidak terdapat hubungan antara: 1) masa kerja dengan tindakan penjamah $(p>\alpha) ; 2)$ fasilitas dengan tindakan penjamah $(p>\alpha)$. Saran diberikan kepada: 1) penjamah agar meningkatkan kepedulian mengenai kemanan pangan dan membiasakan diri untuk menerapkan praktik kebersihan perorangan secara benar dan 
teratur; 2) petugas kesehatan untuk mengadakan pelatihan dan penyuluhan yang dikhususkan untuk penjamah makanan dan memotivasi pengelola maupun penjamah untuk meningkatkan kepedulian dan kesadaran dalam menjaga keamanan makanan; 3) Bagi konsumen agar cermat memilih rumah makan yang tidak hanya menyediakan makanan murah dan enak, tetapi juga memperhatikan kebersihan rumah makan.

Kata Kunci : Tindakan penjamah; rumah makan

\section{PENDAHULUAN}

Tempat Pengelolaan Makanan (TPM) di Indonesia terus meningkat setiap tahunnya. Pada di tahun 2015 jumlah TPM mencapai 65.462 buah TPM dan pada akhir tahun 2016 tercatat hingga 135.864 buah TPM (1). Rumah makan yang baik harus memenuhi standar laik sehat baik itu dari segi bangunan, sarana, karyawan, penyimpanan bahan dan pengamanan terhadap binatang pengganggu. Menurut Keputusan Menteri Kesehatan Republik Indonesia Tahun 2003 Nomor1098 tentang Persyaratan Higiene Sanitasi Rumah Makan / Restoran terdapat beberapa aspek yang diatur dalam penanganan pangan, yaitu penjamah makanan, peralatan, air, bahan makanan, bahan tambahan makanan, penyajian dan sarana (2).

Data dari Badan Pengawasan Obat dan Makanan (BPOM) di Indonesia tahun 2014 terjadi 306 insiden, dan tahun 2015 terjadi 151 insiden. Kasus keracunan di Indonesia dalam bentuk makan siap saji dan katering di rumah makan yang sebagian besar disebabkan oleh makanan yang terkontaminasi oleh penjamah. Penjamah makanan memiliki tanggung jawab dalam pengolahan makanan. Perilaku penjamah dapat dipengaruhi beberapa hal yaitu pengetahuan, sikap, tindakan dan ketersediaan fasilitas atau saran sarana pada rumah makan.Oleh karena itu perilaku penjamah makanan mempunyai peran penting dalam aspek penangan makanan (3). Kasus keracunan pangan ini masih menjadi tugas tahunan bagi petugas kesehatan sehingga perlu ditangani dengan serius.

Kalimantan Selatan pada tahun 2015 berada diurutan ke-6 provinsi dengan KLB keracunan pangan tertinggi se-Indonesia.Sedangkan selama priode 2013-2015 di Kalimantan Selatan terjadi kasus keracunan di beberapa kabupaten/kota. Pada tahun 2013 terjadi kasus keracunan makanan di Kecamatan Batulicin dan Kecamatan Kusan Hilir Kabupaten Tanah Bumbu, pada tahun 2014 terjadi kasus keracunan makanan di Kecamatan Tabunganen dan Kecamatan Tabukan Kabupaten Barito Kuala, dan pada tahun 2015 terjadi kasus keracunan makanan di Kecamatan Gambut, Kertak Hanyar, Simpang Empat dan Martapura Kota Kabupaten Banjar (4).

Berdasarkan data-data yang dikumpulkan dari beberapa artikel, jurnal, berita, dan laporan tahunan dari Puskesmas maupun Dinas Kesehatan wilayah Kabupaten Banjar. Peneliti tertarik untuk melakukan penelitian mengenai keracunan pangan guna mengetahui dan memastikan faktorfaktor yang behubungan dengan tindakan penjamah makanan dalam penanganan makanan di rumah makan yang meliputi beberapa wilayah (Kecamatan Kertak Hanyar terdapat 16 buah rumah makan, Simpang Empat terdapat 4 buah rumah makan, Martapura Kota terdapat 24 buah rumah makandan Gambut terdapat 4 buah rumah makan) yang tempat terjadinya kasus keracunan makanan tahun 2015 di Kabupaten Banjar.

\section{BAHAN DAN CARA PENELITIAN}

Populasi dalam penelitian ini adalah seluruh penjamah makanan yang bekerja di 48 buah rumah makan yang berada wilayah terjadinya kasus KLB keracunan makanan tahun 2015 di Kabupaten Banjaryang meliputi 4 buah kecamatan yaitu kecamatan Kertak Hanyar, Gambut, Simpang Empat dan Martapura Kota.

Sampel dalam penelitian ini adalahpenjamah makanan yang masih aktif bekerja pada 24 buah rumah makan di Martapura Kota wilayah Kabupaten Banjar tahun 2017 yang berjumlah 78 orang penjamah makanan. 
Penelitian ini adalah penelitian analitik kuantitatif menggunakan metode Observasional Research dengan desain Cross Sectional (potong-lintang) adalah rancangan penelitian yang mencakup semua jenis penelitian dengan melakukan pengukuran variabel hanya satu kali dan pada satu saat (5). Setelah semua data terkumpul, maka langkah selanjutnya adalah menganalisis data. Analisis data dalam penelitian ini menggunakan teknik sebagai berikut: a). Analisis Univariat; dilakukan terhadap tiap variabel dari hasil penelitian dengan menggunakan distribusi frekuensi untuk mengetahui gambaran terhadap variabel yang diteliti (6). b). Analisis Bivariat; Analisis yang dilakukan untuk mengetahui hubungan satu variabel bebas dengan variabel terikat yaitu pengaruh tingkat pendidikan, masa kerja, pelatihan, ketersediaan fasilitas atau sarana, pengetahuan dan sikap terhadap tindakan penjamah makanan dalam penanganan makanan. Hasil analisis bivariat dengan uji statistic yang digunakan adalah Korelasi Spearman dengan tingkat kepercayaan $95 \%(\alpha=0,05)(6)$.

\section{HASIL PENELITIAN DAN PEMBAHASAN}

Hasil penelitian menunjukkan hubungan pedidikan, masa kerja, pelatihan, fasilitas, pengetahuan dan sikap dengan tindakan penjamah makanaan yang dapat dilihat pada table-tabel berikut ini:

Tabel 1. Distribusi Frekuensi Tindakan Penjamah Makanan Dalam Penanganan Makanan Berdasarkan Tingkat Pendidikan

\begin{tabular}{|c|c|c|c|c|c|c|}
\hline \multirow[t]{3}{*}{ Tingkat pendidikan } & \multicolumn{6}{|c|}{ Tindakan } \\
\hline & \multicolumn{2}{|c|}{ Baik } & \multicolumn{2}{|c|}{ Kurang } & \multicolumn{2}{|c|}{ Jumlah } \\
\hline & $\mathrm{F}$ & $\%$ & $\mathrm{~F}$ & $\%$ & $\mathrm{f}$ & $\%$ \\
\hline Tinggi(SMA-Universitas) & 30 & 38,5 & 14 & 17,9 & 44 & 56,4 \\
\hline $\begin{array}{l}\text { Rendah (Tidak Sekolah- } \\
\text { SMP) }\end{array}$ & 11 & 14,1 & 23 & 29,5 & 34 & 43,6 \\
\hline Jumlah & 41 & 52,6 & 37 & 47,4 & 78 & 100 \\
\hline
\end{tabular}

Berdasarkan tabel 1 diketahui dari $56,4 \%$ penjamah makanan yang memiliki tingkat pendidikan yang tinggi sebagian besar 38,5\% bertindak baik dalam menangani makanan dan $17,9 \%$ penjamah makanan yang lainnya masih kurang baik dalam bertindak, sedangkan dari $43,6 \%$ penjamah makanan yang memiliki tingkat pendidikan yang rendahhanya sebagian kecil $14,1 \%$ yang bertindak baik dalam menangani makanan dan 29,5\% penjamah makanan sisanya dinyatakan kurang baik dalam bertindak.

Hasil uji statistik denganKorelasi Rank Spearmandiperoleh nilaip $=0,001<$ $\alpha=0,005$ yang berati $\mathrm{HO}$ ditolak dan nilai $r$ menunjukan hasil 0,356 yang artinya terdapat korelasi yang cukup kuat. Sehingga dapat disimpulkan bahwa terdapat hubungan yang bermakna antara pendidikan dengan tindakan penjamah makanan dalam penanganan makanan pada rumah makan wilayah Martapura Kota di Kabupaten Banjar.

Tabel 2. Distribusi Frekuensi Tindakan Penjamah Makanan Dalam Penanganan Makanan Berdasarkan Masa Kerja

\begin{tabular}{ccccccc}
\hline \multirow{2}{*}{ Masa Kerja } & \multicolumn{6}{c}{ Tindakan } \\
\cline { 2 - 8 } & \multicolumn{2}{c}{ Baik } & \multicolumn{2}{c}{ Kurang } & \multicolumn{2}{c}{ Jumlah } \\
\cline { 2 - 8 } & $\mathrm{F}$ & $\%$ & $\mathrm{~F}$ & $\%$ & $\mathrm{~F}$ & $\%$ \\
\hline Lama (>3tahun) & 25 & 32,1 & 16 & 20,5 & 41 & 52,6 \\
Baru ( $\leq$ 3tahun) & 16 & 20,5 & 21 & 26,9 & 37 & 47,4 \\
Jumlah & 41 & 52,6 & 37 & 47,4 & 78 & 100 \\
\hline
\end{tabular}


Berdasarkan tabel 2 diketahui dari $52,6 \%$ penjamah makanan yang masa kerjanya tergolong lama sebagian besar $32,1 \%$ bertindak baik dalam menangani makanan dan 20,5\% penjamah makanan lainnya masih kurang baik dalam bertindak, sedangkan $47,4 \%$ penjamah makanan yang masa kerjanya tergolong baru $20,5 \%$ bertindak baik dalam menangani makanandan $26,9 \%$ penjamah makanan sisanya dinyatakan kurang baik dalam bertindak.
Hasil uji statistik denganKorelasi Rank Spearman diperoleh nilai $p=0,120>$ $\alpha=0,005$ yang berati H0 diterima dan nilai $r$ menunjukan hasil 0,177yang artinya terdapat korelasi yang cukup kuat. Sehingga dapat disimpulkan bahwatidak ada hubungan antara masa kerja dengan tindakan penjamah makanan dalam penanganan makanan pada rumah makan wilayah Martapura Kota di Kabupaten Banjar.

Tabel 3. Distribusi Frekuensi Tindakan Penjamah Makanan Dalam Penanganan Makanan Berdasarkan Pelatihan Pangan

\begin{tabular}{lcccccc}
\hline & \multicolumn{9}{c}{ Tindakan } \\
\cline { 2 - 7 } & \multicolumn{2}{c}{ Baik } & \multicolumn{2}{c}{ Kurang } & \multicolumn{2}{c}{ Jumlah } \\
\cline { 2 - 7 } & $\mathrm{F}$ & $\%$ & $\mathrm{~F}$ & $\%$ & $\mathrm{~F}$ & $\%$ \\
\hline Pernah Mengikuti & 14 & 17,9 & 2 & 2,6 & 16 & 20,5 \\
Belum Pernah mengikuti & 27 & 34,6 & 35 & 44,9 & 62 & 79,5 \\
$\quad$ Jumlah & 41 & 52,5 & 37 & 47,5 & 78 & 100 \\
\hline
\end{tabular}

Berdasarkan tabel 3 diketahui dari $20,5 \%$ penjamah makanan yang sebelumnya pernah mengikuti pelatihan sebagian besar17,9\% bertindak baik dalam menangani makanan dan 2,6\% penjamah makanan lainnya masih kurang baik dalam bertindak, sedangkan dari79,5\% penjamah makanan yang tidak pernah mengikuti pelatihan $34,5 \%$ bertindak baik dalam menangani makanan dan sebagian besar 44,9\% penjamah makanan sisanya dinyatakan kurang baik dalam bertindak.
Hasil uji statistik denganKorelasi Rank Spearman diperoleh nilaip $=0,001<$ $\alpha=0,005$ yang berati $\mathrm{HO}$ ditolak dan nilai $r$ menunjukan hasil 0,355 yang artinya terdapat korelasi yang cukup kuat. Sehingga dapat disimpulkan bahwa terdapat hubungan yang bermakna antara pelatihan mengenai pangan dengan tindakan penjamah makanan dalam penanganan makanan pada rumah makan wilayah Martapura Kota di Kabupaten Banjar.

Tabel 4. Distribusi Frekuensi Tindakan Penjamah Makanan Dalam Penanganan Makanan Berdasarkan Ketersediaan Fasilitas

\begin{tabular}{lcccccc}
\hline Fasilitas atau Sarana & \multicolumn{6}{c}{ Tindakan } \\
\cline { 2 - 7 } & \multicolumn{2}{c}{ Baik } & \multicolumn{2}{c}{ Kurang } & \multicolumn{2}{c}{ Jumlah } \\
\cline { 2 - 7 } & $\mathrm{F}$ & $\%$ & $\mathrm{~F}$ & $\%$ & $\mathrm{f}$ & $\%$ \\
\hline Lengkap & 22 & 28,2 & 16 & 20,5 & 38 & 48,7 \\
Kurang Lengkap & 19 & 24,4 & 21 & 26,9 & 40 & 51,3 \\
Jumlah & 41 & 52,6 & 37 & 47,4 & 78 & 100 \\
\hline
\end{tabular}

Berdasarkan tabel 4 diketahui dari $48,7 \%$ penjamah makanan yang bekerja di rumah makan yang memiliki fasilitas lengkap sebagian besar28,2\% bertindak baik dalam menangani makanan dan 20,5\% penjamah makanan lainnya masih kurang baik dalam bertindak, sedangkan dari 51,3\% penjamah makanan yang bekerja di rumah makan yang fasilitasnya tergolong tidak lengkap 24,4\% bertindak baik dalam menangani makanandan 26,9\% penjamah 
Perdana Oktavianus Kurniawan, Darmiah, Rahmawati. Faktor-Faktor Yang Berhubungan Dengan Tindakan Penjamah Dalam Penanganan Makanan Pada

makanan sisanya dinyatakan kurang baik dalam bertindak.

Hasil uji statistik denganKorelasi Rank Spearman diperoleh nilai $p=0,365>$ $\alpha=0,005$ yang berati H0 diterima dan nilai $r$ menunjukan hasil 0,104. Sehingga dapat disimpulkan bahwa tidak terdapat hubungan antara fasilitas dengan tindakan penjamah makanan dalam penanganan makanan pada rumah makan wilayah Martapura Kota di Kabupaten Banjar.

Tabel 5. Distribusi Frekuensi Tindakan Penjamah Makanan Dalam Penanganan Makanan Berdasarkan Tingkat Pengetahuan

\begin{tabular}{lcccccc}
\hline \multirow{2}{*}{ Pengetahuan } & \multicolumn{6}{c}{ Tindakan } \\
\cline { 2 - 8 } & \multicolumn{2}{c}{ Baik } & \multicolumn{2}{c}{ Kurang } & \multicolumn{2}{c}{ Jumlah } \\
\cline { 2 - 8 } & $\mathrm{F}$ & $\%$ & $\mathrm{~F}$ & $\%$ & $\mathrm{~F}$ & $\%$ \\
\hline Baik & 26 & 33,3 & 11 & 14,1 & 37 & 47,4 \\
Kurang & 15 & 19,3 & 26 & 33,3 & 41 & 52,6 \\
Jumlah & 41 & 52,6 & 37 & 47,4 & 78 & 100 \\
\hline
\end{tabular}

Berdasarkan tabel 5 diketahui dari 47,4\% penjamah makanan yang memiliki pengetahuan baik sebagian besar33,3\% bertindak baik dalam menangani makanan dan $14,1 \%$ penjamah makanan lainnya masih kurang baik dalam bertindak, sedangkan dari 52,6\% penjamah makanan yang memiliki pengetahuan kurang baik sebagian kecil 19,3\% bertindak baik dalam menangani makanan dan 33,3\% penjamah makanan sisanya dinyatakan kurang baik dalam bertindak.

Hasil uji statistik dengan Korelasi Rank Spearman diperoleh nilai $p=0,003<$ $\alpha=0,005$ yang berati $\mathrm{H} 0$ ditolak dan nilai $r$ menunjukan hasil 0,337 yang artinya terdapat korelasi yang cukup kuat. Sehingga dapat disimpulkan bahwa terdapat hubungan yang bermakna antara pengetahuan dengan tindakan penjamah makanan dalam penanganan makanan pada rumah makan wilayah Martapura Kota.

Tabel 6. Distribusi Frekuensi Tindakan Penjamah Makanan Dalam Penanganan Makanan Berdasarkan Sikap

\begin{tabular}{|c|c|c|c|c|c|c|}
\hline \multirow[t]{3}{*}{ Sikap } & \multicolumn{6}{|c|}{ Tindakan } \\
\hline & \multicolumn{2}{|c|}{ Baik } & \multicolumn{2}{|c|}{ Kurang } & \multicolumn{2}{|c|}{ Jumlah } \\
\hline & $\mathrm{F}$ & $\%$ & $\mathrm{~F}$ & $\%$ & $\mathrm{~F}$ & $\%$ \\
\hline Mendukung & 30 & 38,5 & 15 & 19,2 & 45 & 57,7 \\
\hline Tidak Mendukung & 11 & 14,1 & 22 & 28,2 & 33 & 42,3 \\
\hline Jumlah & 41 & 52,6 & 37 & 47,4 & 78 & 100 \\
\hline
\end{tabular}

$57,7 \%$ penjamah makanan yang memiliki sikap yang mendukung sebagian besar $38,5 \%$ bertindak baik dalam menangani makanan dan 19,2\% penjamah makanan lainnya masih kurang baik dalam bertindak, sedangkan dari 42,3\% penjamah makanan yang memiliki sikap yang tidak mendukung sebagian kecil $14,1 \%$ bertindak baik dalam menangani makanan dan 28,2\% penjamah makanan
Hasil uji statistik denganKorelasi Rank Spearman diperoleh nilaip $=0,001<$ $\alpha=0,005$ yang berati $\mathrm{H} 0$ ditolak dan nilai $r$ menunjukan hasil 0,330 yang artinya terdapat korelasi yang cukup kuat. Sehingga dapat disimpulkan bahwa terdapat hubungan yang bermakna antara pendidikan dengan tindakan penjamah makanan dalam penanganan makanan pada rumah makan wilayah Martapura Kota di Kabupaten Banjar. 


\section{KESIMPULAN DAN SARAN}

Berdasarkan hasil pengamatan dan analisis data pada penelitian yang telah dilakukan dapat disimpulkan ada hubungan yang bermakna antara tingkat pendidikan dan tindakan penjamah makanan dalam penanganan makanan pada rumah makan di Martapura Kota wilayah Kabupaten Banjar dengan nilai $(p<0,005)$, tidak terdapat hubungan antara masa kerja dengan tindakan penjamah makanan dalam penanganan makanan pada rumah makan di Martapura Kota wilayah Kabupaten Banjar dengan nilai ( $p>0,005)$, ada hubungan yang bermakna antara pelatihan mengenai pangan dengan tindakan penjamah makanan dalam penanganan makanan pada rumah makan di Martapura Kota wilayah Kabupaten Banjar dengan nilai $(p<0,005)$, tidak terdapat hubungan antara fasilitas dengan tindakan penjamah makanan dalam penanganan makanan pada rumah makan di Martapura Kota wilayah Kabupaten Banjar dengan nilai ( $p>0,005)$, ada hubungan yang bermakna antara pengetahuan dengan tindakan penjamah makanan dalam penanganan makanan pada rumah makan di Martapura Kota wilayah Kabupaten Banjar dengan nilai $(p<0,005)$ dan ada hubungan yang bermakna antara sikap dengan tindakan penjamah makanan dalam penanganan makanan pada rumah makan di Martapura Kota wilayah Kabupaten Banjar dengan nilai $(p<0,005)$.

Bagi penjamah makanan agar meningkatkan kepedulian dan memperhatikan keamanan makanan pada saat pengolahan dan penyajian, membuka diri untuk meminta masukan dari orang lain terkait dengan penanganan makanan dan keamanan pangan, menerapkan masukan atau informasi yang diperoleh dalam menjaga kualitas keamanan pangan, dan embiasakan diri untuk menerapkan praktik kebersihan perorangan secara benar dan teratur.

Bagi Puskesmas atau Petugas Sanitasi agar memberikan informasi yang memiliki dampak penekanan bagi konsumen tentang bahaya pengolahan makanan yang tidak aman, mengadakan pelatihan dan penyuluhan yang dikhususkan untuk penjamah makanan, memanfaatkan berbagai media dalam pemberian informasi kepada penjamah makanan, memotivasi pengelola dan penjamah rumah makan untuk meningkatkan kepedulian dan kesadaran dalam menjaga kualitas keamanan makanan, misalnya mengajukan anggaran kepada pemerintah untuk memberikan penghargaan ke-beberapa rumah makan.

Bagi konsumen agar cermat memilih rumah makan yang tidak hanya menyediakan makanan murah dan enak, tetapi juga memperhatikan kebersihan rumah makan tersebut, meningkatkan kewaspadaan terhadap makanan yang tidak aman atau diolah dengan cara yang tidak bersih dan sehat dan berpartisipasi aktif dalam upaya meminimalisir terjadinya gangguan kesehatan akibat makanan yang tidak sehat dengan melaporkan kepada pihak Puskesmas, segala kejanggalan atau temuan menyimpang yang dijumpai saat mengonsumsi pangan di rumah makan.

\section{KEPUSTAKAAN}

1. Kepmenkes RI, 2015. Lampriran 7.8 Pressentase Tempat Pengelolan Makanan Yang Memenuhi Syarat Higiene Sanitasi.

2. WHO, 2006.Penyakit Bawaan Makanan, Fokus Pendidikan Kesehatan. Jakarta: ECG.

3. Harisa.T, 2011.Tinjauan Pengetahuan dan Sikap Penjamah Makanan Tentang Keamanan Pangandan Sanitasi di Rumah Makan Sekitar Kampus IPB.

4. Ningtyas.A, 2016. Hubungan Penerapan Prinsip Hygine Sanitasi Makanan Dengan Cemaran Mikroba Pada Makanan Jadi Kantin Sekolah Wilayah Kerja Puskesmas Tabukan

5. Notoatmodjo.S, 2007. Promosi Kesehatan dan Ilmu Perilaku.Jakarta : RinekaCipta.

6. Notoatmodjo.S, 2012. Metodologi Penelitian Kesehatan. Jakarta : RinekaCipta. 